\title{
CT Scan and Surgery in Subdural Empyema: A Case Report
}

\author{
Major S P Sahi, \\ MB, BS, MRCP (UK), RAMC \\ Senior Specialist in Medicine \\ British Military Hospital Munster West Germany \\ Group Captain (Retd) W R H Downey \\ MB, FRCP, DCH \\ Consultant Physician \\ British Military Hospital Hannover West Germany
}

SUMMARY: A high index of suspicion is required to pick up cases of subdural empyema in clinical practice. CT scan may be normal in the initial stages. Early neurosurgical intervention is desirable to reduce mortality and morbidity in this condition.

\section{Introduction}

Subdural empyema is a rare clinical problem in a general medical ward. The mortality and morbidity figures vary in different series, but the overall mortality, even in the best centres, remains distressingly high at around $20-30 \%{ }^{1,2}$. One major factor contributing to this high mortality is the delay in the diagnosis often due to a low index of suspicion and over-reliance on CT Scan ${ }^{3}$. Even a contrast enhanced scan may give little information in the early stages.

The condition is usually associated with local spread of infection from sinuses, middle ear, osteomyelitis of skull bones, or following meningitis. It may also arise as a result of direct penetrating injury or following surgery. Rarely, it has been reported in association with metastatic spread of infection from a distant focus in a patient with congenital cyanotic heart disease.

The timely institution of antibiotic treatment covering both aerobic and anaerobic organisms, and the surgical evacuation of pus, following appropriate investigations, can lead to a favourable outcome. Parenteral penicillin, metronidazole and flucloxacillin are a reasonable combination to start with, while awaiting the results of bacteriological confirmation where this is possible ${ }^{3}$.

We present the case of a young man who sustained an injury to his forehead due to human teeth. This led to the development of osteomyelitis, and subdural empyema ensued as a complication.

\section{Case Report}

A 31 year old sergeant was admitted to hospital from a medical centre with a few days' history of headache, pyrexia and drowsiness. He had also complained of tingling and numbness, along with slight weakness, on the left side of his body.

A month before this illness began, he had sustained an injury to his forehead at a party due to human teeth. This injury was treated by primary suture. Following this, a purulent discharge was noted from the wound, and this persisted until the day of admission.
In the past he had enjoyed good health apart from orthopaedic consultations for painful knees.

On admission, he was pyrexial (temperature $39^{\circ} \mathrm{C}$ ) and conscious, but confused. His pulse rate was $40 / \mathrm{m}$, and blood pressure was $120 / 80 \mathrm{~mm} \mathrm{Hg}$. Chest, cardieo vascular and abdominal examination did not reveal an abnormal findings.

The central nervous system examination revealedo marked neck rigidity and photophobia. There was sligh motor weakness and inco-ordination with exaggerate $\Phi$ reflexes on the left side. The plantar response wag downgoing. The patient was too confused to underge sensory examination.

Examination of the fundi showed engorged veins witg blurred disc margins. Local examination of scal revealed a small lacerated wound on the forehead from which there was a purulent discharge. Laboratory investigations produced the following results: $\mathbf{H b}-12-$ $3 \mathrm{gm} / \mathrm{dL}$; WBC- $11.6 \times 10^{9} / \mathrm{L}$ (71\% polys); urea and electrolytes within normal limit. Blood cultures subsequently did not reveal a significant growth of any pathogens. X-rays of chest, and skull and sinuses were normal.

A diagnosis of intracranial abscess was suspected and after the essential initial investigations the patient was transferred to the Medical School of Hannover for CT scan.

The first CT scan failed to reveal any intracranial pathology and in view of the clinical findings the patient had a lumbar puncture which showed a high CSF pressure, a high protein and cell count, but no stainable bacteria, and no growth of pathogens on culture.

Penicillin, metronidazole and flucloxacillin were begun and the patient was given steroids to reduce the intracranial pressure. Three days later, in view of the deteriorating level of consciousness, he had a repeat CT scan which now revealed a collection of pus in the subdural space in the temporo-parietal and frontal regions on the right side.

Following emergency surgical evacuation of pus, the 
patient made a complete recovery. A contrast enhanced

CT scan on subsequent follow up demonstrated osteomyelitis of the frontal bone with an underlying collection of pus. He again underwent surgical evacuation, this time with the removal of osteomyelitic bone. He made an uneventful recovery following this.

\section{Conclusions}

In its early stages a subdural empyema can easily be missed in patients who present with a meningitis-like picture, without any neurological latcralising signs, and with equivocal CT findings. In cases such as this, any site of infection near the cranial vault should arouse suspicion if the diagnosis is not to be missed. Lumbar puncture should be deferred if possible, as it may lead to coning with fatal consequences ${ }^{4}$.

In $30 \%$ of cases the CT scan may be normal. Readiness on the part of the physician to repeat the scan may resolve the radiological diagnostic difficultics in some situations ${ }^{3}$; this was certainly true in our case.

Prompt surgical intervention is essential to prevent death. It is felt that in those cases where there is a strong possibility of subdural empyema, but where there are minimal localising signs and an equivocal CT scan, exploratory burr holes, with suitable antibiotic cover, may be life saving.

\section{Acknowledgements}

I would like to thank Lt Col C R Winfield RAMC for his advice in preparing the manuscript and Ms Caroline Fisher for typing this case report.

\section{REFERENCES}

1. Farkas A G and Marks $\mathbf{J}$ C, Subdural empyema: an important diagnosis not to miss. Br Med I 1986; 293: 118119.

2. Kaufman D M. Militer M H and Steigbigel N H. Subdural Empyema: analysis of 17 recent cases and review of literature. Medicine 1975; 54: 485-498.

3. Hodges I, AnsLow P and Gilltit G. Subdural Empyema continuing diagnostic problems in the CT Scan Era. $Q J$ Med 1986: 59: 387-93.

4. Duffy G P. Lumbar Puncture in Presence of Raised Intracranial Pressure. Br Med J 1969; 1: 407-409.

\section{ROYAL COLLEGE OF GENERAL PRACTITIONERS SCHERING SCHOLARSHIP FOR TRAINERS IN GENERAL PRACTICE}

In 1983 Schering Health Care Ltd, through its Education Services Division, have provided five Scholarships to the value of $£ 1000$ each, to General Practitioners, Vocational Trainers and Course Organisers.

The aim of the Scholarships is to enable General Practice Teachers to enhance their knowledge and skills by embarking on original projects which should have a new and broader perspective in the teaching of General Practice.

One of the 1987 Schering Scholarships was awarded to Lt Col J C Richardson RAMC. He will be making a 'distance learning programme' for the continuation training of RAMC General Practicc Managers who have to work in comparative isolation abroad.

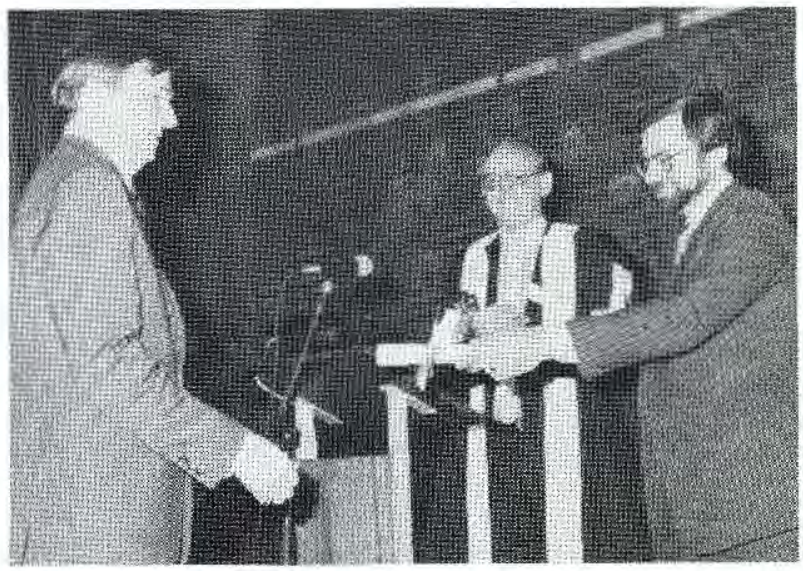

Lt Col John Richardson RAMC receives his Award from a Schering Representative and Dr Michael Varnam (Education Division, Royal College of General Practitioners). 